\title{
Work in Progress: Sustainable Engineering Education in the Mechanical En- gineering Curriculum
}

\section{Dr. Huihui Qi, Grand Valley State University}

Dr. Qi is an assistant professor in Mechanical Engineering at Grand Valley State University. She earned her Ph.D. degree in Mechanical Engineering from Rutgers University. Dr. Qi's teaching interests include Engineering Design, Solid Mechanics, Mechanical System Design and Computer Aided Design. Dr. Qi’s areas of interest and expertise include design sustainability, Life Cycle Assessment, decision making for optimal design, and Computer Aided Design. 


\title{
Work in Progress: Sustainable Engineering Education in Mechanical Engineering Curriculum
}

\author{
Dr. Huihui Qi, Grand Valley State University
}

\section{Introduction}

Sustainable development is a global goal nowadays. Engineers play an unreplaceable role in the global sustainable development. As a result, the importance of sustainable engineering education has been widely recognized by engineering educators. In addition, ABET [1] has two students outcome criteria for sustainability: students should have (c) an ability to design a system, component or process to meet desired needs within realistic constraints such as economic, environmental, social, political, ethical, health and safety, manufacturability and sustainability; and $(\mathrm{h})$ the board education necessary to understand the impact of engineering solution in a global, economic, environmental, and social context.

To accommodate industry needs, and respond to ABET requirements, many institutions have created their ways to increase the level of education about sustainable engineering through multiple different ways. For example, University of Texas, Arlington integrated sustainable engineering education throughout the "Engineering Sustainable Engineers" program [2]; They also created an internship program to provide students an opportunity to be educated about sustainability [3]; University of Colorado, Boulder introduced the first-year civil engineering students to sustainability [4]; Carnegie Mellon University, University of Texas, EL Paso, Galveston College and CETYS University created a community service learning opportunity to provide the students and faculty to gain experience in sustainable engineering development in Mexico [5].

At Grand Valley State University, there are limited technical elective courses about sustainable engineering and most with an emphasis on renewable energy. More courses about sustainable engineering are needed in Mechanical Engineering curriculum, as has been mentioned in alumni survey. A new course entitled "Sustainable Engineering Design" was designed to as a new addition to the senior level technical electives for Mechanical Engineering students with a comprehensive review of sustainable development issues, and sustainable engineering principles and methods that with more content than sustainable energy. The main goal of the course is to aim to provide students with a comprehensive and broad understanding the importance of the sustainability, and introduce sustainability principles, and how they should be taken into consideration in all stages of engineering design/ manufacturing process of a product and engineering system. It also aims to promote innovation and creativity in design/ manufacturing process with the sustainability as one important constraint. The learning objectives after the students take the course are:

a. Have a good understanding of the concept of sustainability, including the history, and laws related to sustainability 
b. Evaluate a product/ engineering system's environmental impacts using Life Cycle Assessment

c. Design/ redesign a product/ engineering system to using the engineering principles to improve environmental impacts

The achievement of these goals was assessed through students' self-evaluations and analysis of students' coursework. In addition, the objectives are also planned to be assessed through students' capstone senior projects. But at the time of creation of this work-in-progress paper, the students who took this course have not worked on their senior project yet, as a result, this part of the assessment is planned to be conducted once the students worked on their senior projects. To extend and complete this work-in-progress, it is planned to investigate if the students make their design decisions with the consideration of sustainability and whether the students use the tools and techniques learned from this class to attain more sustainable designs.

This sustainable engineering design course integrated classroom learning, guest lecture, case studies, project-based learning, and field trips. The traditional classroom learning including case studies take about $80 \%$ of the class time, it helps students gain knowledge about sustainable engineering design principles. The 4 field trips and guest speech take about $20 \%$ of class time, it provides an opportunity to expose the students to see how sustainability principles are implemented in reality, to enhance their understanding of the textbook knowledge. Project-based learning is mainly completed outside of the classroom through a semester assessment and redesign project. Different class elements were delivered to students in an inter-woven style, and sometimes different elements showed up in the same class period.

\section{Course Structure}

This course was designed as an upper division mechanical engineering elective course, typically offered to senior students and juniors if they met the prerequisite. The prerequisite for junior students is mechanics of materials, calculus I, II and III, Computer-Aided Design and Finite Element Analysis.

The course was offered a semester before the students finish their senior project, so hopefully, the senior students could find opportunities to implement the sustainable design principles to the industry-sponsored senior projects.

With the course objectives mentioned in the previous section, the 14 week-long, 3 credits course was carefully planned with a list of topics below:

- Introduction to Sustainability (1 week)

○ Concept of sustainability

- History of sustainable development

- Drivers for sustainable development

○ Introduction to sustainable engineering 
- Sustainable development for developing countries and local sustainable engineering projects (Guest speech)

- Life Cycle Assessment (3 weeks)

○ Introduction to Life Cycle Assessment

- Environmental impact indicators

- LCA case study

- LCA with software

- Design Optimization (3 weeks)

- Mathematical preparation of optimization

- Material reduction by design optimization

○ Manufacturing optimization

- Waste management ( 2 weeks)

- Recovery and recycle of materials

- Local Material Recovery Center tour

- Local Waste to Energy facility tour

- Local recycle company tour

- Materials selection (2 weeks)

$\circ$ Properties of common engineering materials

○ Material sourcing strategy

○ Material selection strategy for sustainability

- Energy (2 weeks)

- Energy basics

○ Fossil Fuels

- Renewable energy

- Solar garden facility tour

- Cost analysis (1 week)

The teaching methods included traditional lectures (theories and case studies), facility tours and guest speech. The students' learning outcomes were assessed through assignments, exam and quizzes, and project.

Discussion of Case studies and examples during class

At the beginning of the semester, it was emphasized to the students that there was no "one method fits all" for sustainable engineering, and creativity and innovation are critical. Case studies and examples were helpful to learn the application of different methods in successful cases. For example, when Life Cycle Assessment was introduced, a milk packaging Life Cycle Assessment created by WRAP [6] was discussed as a case study. The milk packaging Life Cycle Assessment compared the environmental impacts of six different pasteurized milk packaging in the UK. The discussion of this case study gives the students a good sample of Life Cycle Assessments report, as well as helping students to have a better understanding of different materials and manufacturing and their environmental impacts. 
Another example was the "Amsterdam's Schiphol Airport Unrinal with fly" as shown in figure 1, that was used to encourage students' creative thinking towards sustainability. The value of the "Amsterdam's Schiphol Airport Unrinal with fly" has been well studied by the economist and psychologist. This case study was considered a good example of Nudge Theory [7] by Richard Thaler, winner of 2017 Nobel prize in economics. But the value of this case study from a sustainable engineering perspective was emphasized in class. During class, the students were challenged with the urinal redesign problem:

"Urinals are actually designed to minimize unwanted splashing. This works best if the stream is aimed to a certain area of the urinal bowl. But at Schiphol International Airport in Amsterdam, splash around the urinals in the restroom had been a problem. Brainstorm with your group, what ideas do you propose to solve this problem? Do not forget sustainability!"

Students were asked to have a group discussion for 10 minutes, then proposed a conceptual solution to the class. The students were very innovative for this brainstorming activities, their proposed solution included building a system to collect rainwater to clean the urinal, using robots to clean, and redesigning the shape of the urinal. Even the solution was all different, but the students all tried to create a complex engineering system. After each group presented their solution, the Urinal with the fly at Schiphol International Airport in Amsterdam was presented as shown in Figure 1.

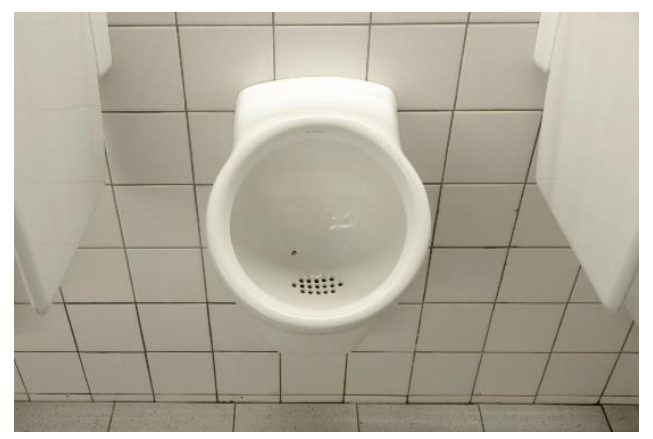

Figure 1. The Urinal with the fly at Schiphol International Airport in Amsterdam [8]

The most important points made through this case study was:

- Innovation and creativity are needed for problem-solving for sustainable engineering. Of course, the students were highly complimented for their creative ideas that were formulated in a short time period.

- Sustainable engineering thinking: solve the problem effectively use the least amount of resources.

Facility tours

Four facility trips were carefully selected for the course, as an important part to give the students a real experience on the topic of materials recycle and reuse, as well renewable energy. The four 
facility tours were a Local Material recovery Center tour, Local Waste to Energy facility tour, Recycle Company tour and Solar garden facility tour. The duration of the tour varied from 1 hour to 1.5 hours. The Local Material recovery Center tour, Local Waste to Energy facility tour and Recycle Company tour gave the students an opportunity to fully understand the concept of 4 Rs in terms of sustainable engineering design in material: reduce, reuse, recovery and recycle.

One challenge to integrate the facility tours into class learning was the scheduling. Each of the facility had a regular operation time, which usually closes at $5 \mathrm{pm}$. But the class time was 5:30 pm to 6:45 each Tuesday and Thursday. It caused a challenge in regards to the coordination between the class and the facilities. To resolve this issue, the class went to the material and recovery center and waste to energy facility in small groups during a time that works the best for them. For the Recycle Company and Solar Garden tour, special arrangements were coordinated with the facilities to accommodate students' time.

For each of the tour, students were assigned a trip report. The trip reports assignments required students to write a summary and reflection about the trip, as well as respond to specific questions like "what is the procedure of materials recycles?" "what did you learn from the facility tour?" These questions helped students to attend the tour with a purpose. Not only the students got the chance to visualize the concept learned from class in reality, but also they had a deeper thinking on the topic. For example, a lot of the students expressed in the trip report " the material recovery center tour was an eye-opening experience" " the tour made me realize how much waste we create and everyone should practice sustainability principles in my daily life" "it was very impressive to see the materials recovery center's innovative machines". All of the students believe the tours were enjoyable and valuable part of their learning process about sustainable engineering.

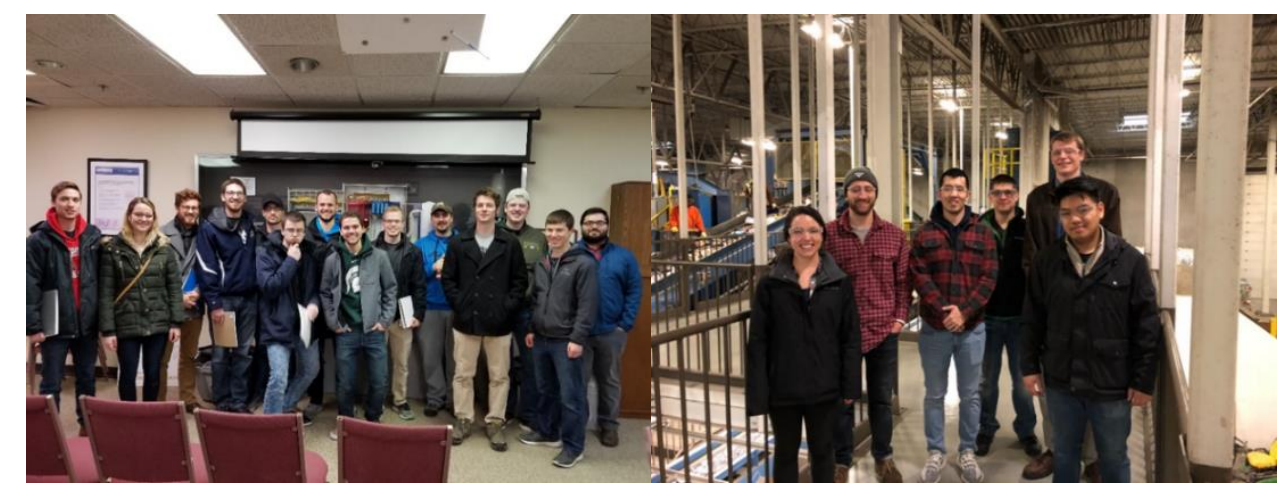

Figure 2. Students were taking the tour at the Material Recovery Center and Waste to Energy Center

\section{Guest Speech}

A guest speaker from the local government environmental organization was invited to give a speech in the first week of the class. The speaker reviewed sustainable development engineering 
projects for the developing world that she has been involved, as well as sustainable project planning and the current sustainable projects happening in the city of Grand Rapids. The benefit of having a guest speaker was to give a real-world experience in the field that some engineering faculty may have limited experience on, such as sustainability-related policymaking.

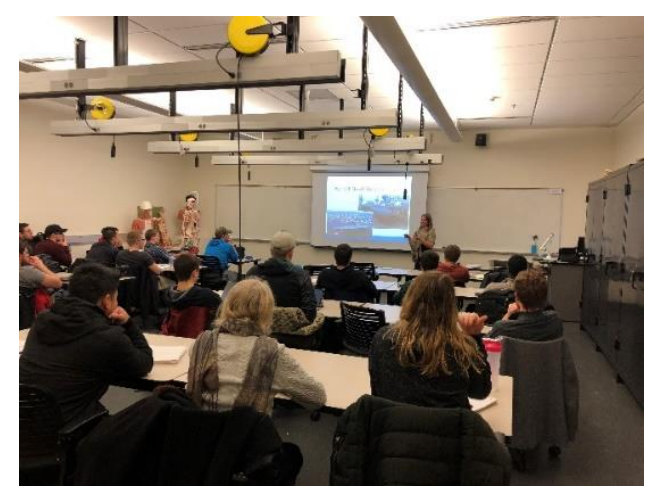

Figure 3. Guest Speech at the beginning of the semester

Assignment

Assignments were usually assigned to students after each lecture. The format of the assignments included review and application of knowledge learned from lectures, as well as creative works that aim to inspires students' deeper and wider thinking about sustainability. Some examples of these assignments included:

- Look around the engineering building, what system is not sustainable? Propose a plan to make changes to it.

- Watch a movie/ documentary that is related to the concept of sustainability, write a review about the movie/documentary. The review should include at least two parts: the summary of the movie/ documentary content, the underlying message from the movie. (A list of suggested movie/ documentary were given).

Project

The course project played an important role in providing an opportunity to the students to implement the sustainable engineering principles into design application. The project was assigned at the beginning of the semester, right after the class has gained some understanding of sustainable engineering. There were mainly three stages of the project: project proposal, Life Cycle Assessment of product alternatives, and redesign of the product for better environmental impact performance. Students worked in a group of 2 or 3 students, and they were given the opportunity to select the project topic that they will conduct a Life Cycle Assessment and redesign. During the life cycle assessment phase, students created goal and scope definition, life cycle inventory analysis by themselves, and used LCA software to conduct life cycle impact analysis for $\mathrm{N}$ product alternatives, where $\mathrm{N}$ equal to the number of group members in the team. Then at the final phase of the project, students adopted at least one sustainable engineering principle to create a new product, then compare the new product's environmental impact 
performance with the existing $\mathrm{N}$ products alternatives. Through this project, students applied Life Cycle Assessment to a real design problem and improved the environmental impact performance through the creative and innovative use of sustainable engineering principles learned in class.

\section{Course outcomes assessment}

In order to assess the effectiveness of the course, a series of surveys have been conducted throughout the semester. Especially, surveys have been made about students' interest in sustainability, students' awareness of sustainability, the effectiveness of field trips and guest speech, and effectiveness of the course on students' sustainability knowledge progress. Overall, the course reached a big success from all perspectives. Data are presented and discussed in the next session.

Assessment of students' interest in sustainability

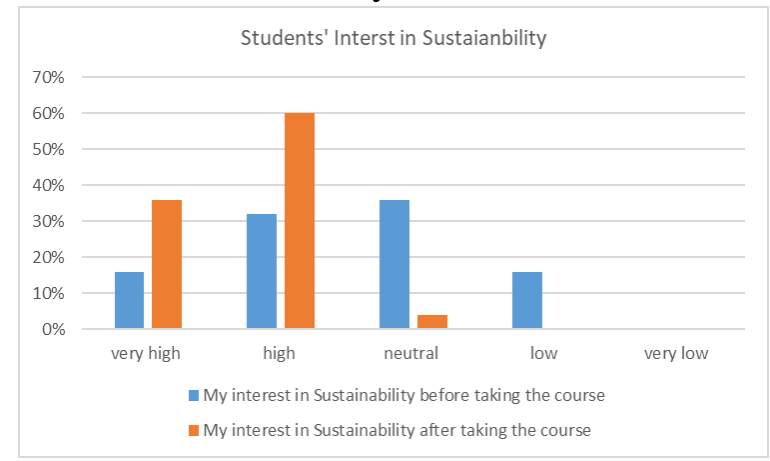

Figure 4. Assessment of students interest in sustainability $(\mathrm{N}=25)$

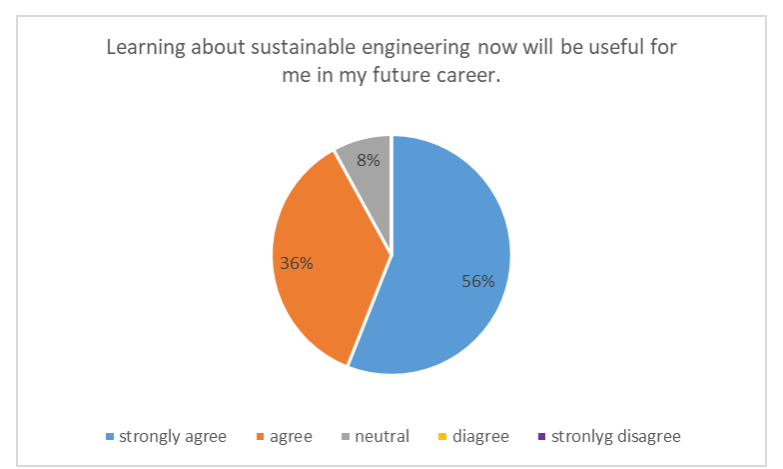

Figure 5. Students' opinion on the impact of learning sustainable engineering to their future career $(\mathrm{N}=25)$

With the class size of 25, before the course, students were exposed to very limited information about sustainability and its application in engineering. About $52 \%$ of the class have neutral or low interest in the class subject matter. Later learned in conversations with students, most students actually did not really know what it means by "sustainability", as well as what engineers 
could do about sustainability. The effectiveness was obvious for this class in terms of increasing students' interest in sustainability. $96 \%$ of the students have high or very high interest in sustainability after taking the class. In addition, $92 \%$ of the students believed learning about sustainable engineering now would be useful for their future career.

Students' awareness of sustainability assessment

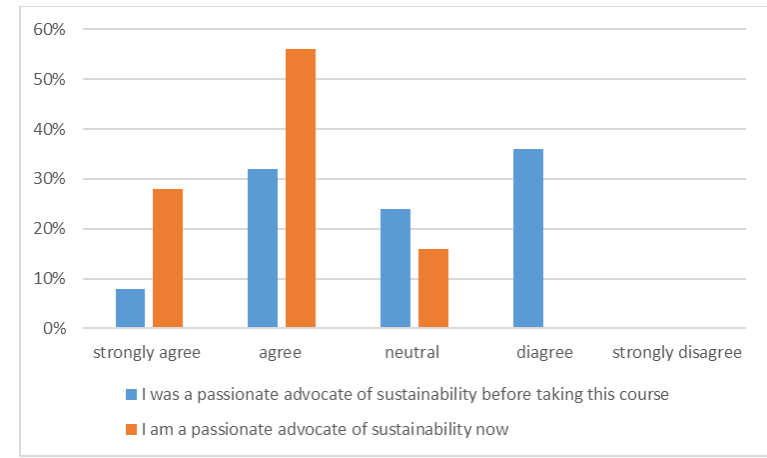

Figure 6. Students' passion for being an advocate of sustainability $(\mathrm{N}=25)$

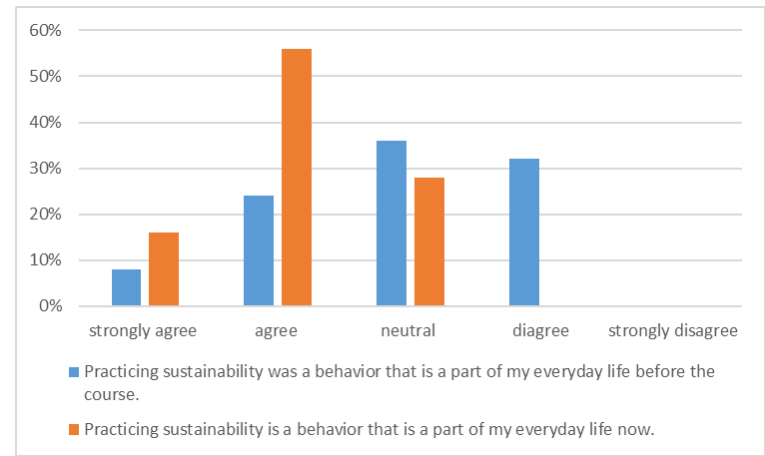

Figure 7. Students practice on sustainability in daily life $(\mathrm{N}=25)$

It is important for me to learn how engineers can make the world more sustainable.

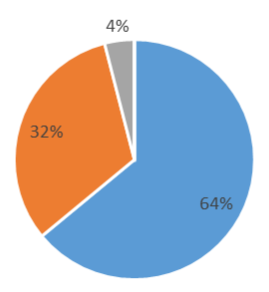

- Strongly agree - Agree = Neutral = Disagree - Strongly disagree

Figure 8. Students sense of responsibility for sustainable development through engineering $(\mathrm{N}=25)$ 
Sustainability is a key component of Mechanical engineering

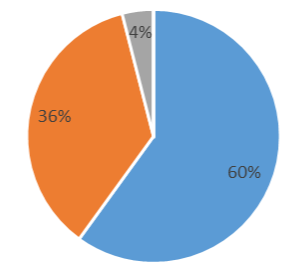

Figure 9. Students' awareness of the importance of sustainable engineering $(\mathrm{N}=25)$

Only $40 \%$ of the students agreed or strongly agreed that they were passionate advocates of sustainability before taking this course. But after taking the class, $84 \%$ of the students agreed or strongly agreed that they were passionate advocates of sustainability. A lot of the students who claim "disagree" they were a passionate advocate of sustainability, pointed out that they were not again it, they were ignorant of it. This proved that offer students a sustainable engineering course is very necessary to inspire engineers' realization on the issue.

The comparison has also been made to compare students' everyday life habits change for sustainability. Before taking the class, only $32 \%$ of the students practice sustainability through daily life, such as recycling aluminum cans, using public transportation and so on. After taking the course, the percentage of students practice sustainable behavior increased by $40 \%$.

After taking the course, $96 \%$ of the students believe it is important for engineers to learn how to make the world more sustainable, and it is key for mechanical engineers, as well as all engineering disciplines.

Assessment of the effectiveness of field trips and the guest speech

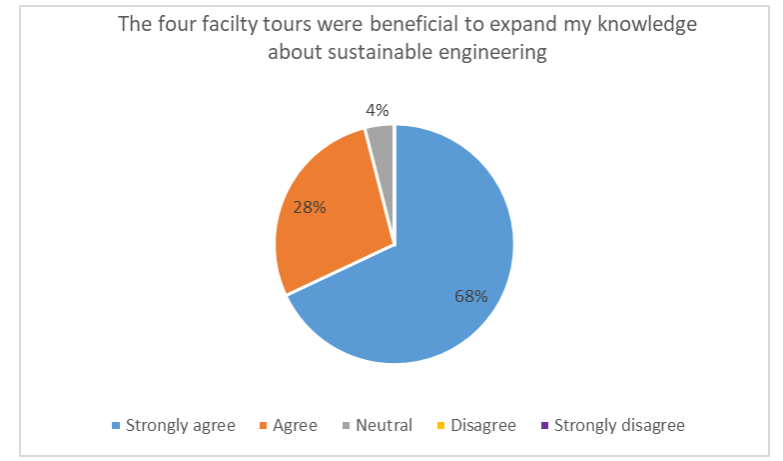

Figure 10. Students' feedbacks on facility tours $(\mathrm{N}=25)$ 


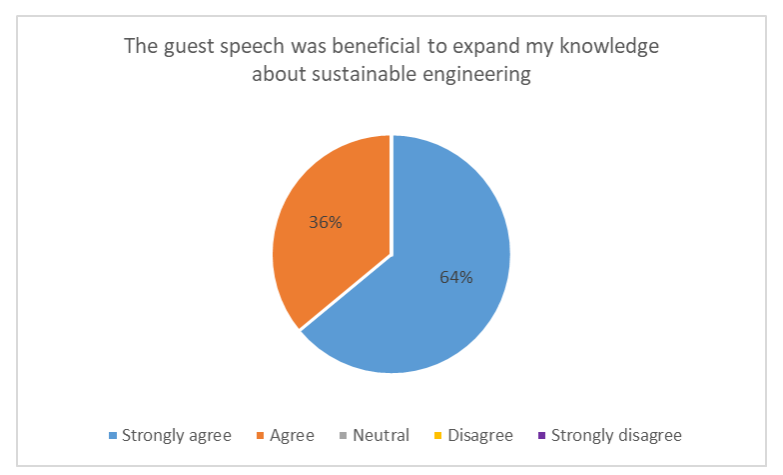

Figure 11. Students' feedbacks on guest speech $(\mathrm{N}=25)$

96\% students agreed or strongly agreed that the facility tours were beneficial to their study about sustainable engineering, and $100 \%$ of the students agreed or strongly agreed that the guest speech was beneficial to their study about sustainable engineering.

The effectiveness of the course on students' Sustainability knowledge progress

The course increased my ability to explain sustainability concepts

and terminology.

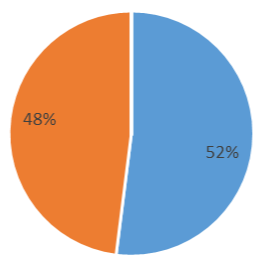

- Strongly agree - Agree = Neutral = Disagree - Strongly disagree

Figure 12. The effectiveness of the course to increase students' understanding sustainability $(\mathrm{N}=25)$

The course increased my ability to evaluate potential engineering

solutions based on sustainability

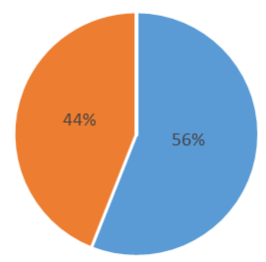

- Strongly agree - Agree = Neutral = Disagree - Strongly disagree

Figure 13. The effectiveness of the course on students' Sustainability knowledge progress $(\mathrm{N}=25)$ 
$100 \%$ students agreed or strongly agreed that the course has increased their knowledge on sustainable engineering, as well as the ability to evaluate potential engineering solution based on sustainability.

The beginning of the semester and mid-semester sustainable engineering conceptual knowledge evaluation

At the first day of class, a list of conceptual questions about sustainable engineering was given to the class, in order to understand students' knowledge about sustainable engineering:

- Question 1: What does sustainability mean to you now? How do you define sustainability?

- Question 2: Who can contribute to sustainability? In what way(s)?

- Question 3: What can engineers do for sustainability?

- Question 4: What sustainable engineering design tool/principle do you know?

- Question 5: Have you heard of any individual or organization take any initiatives for sustainability? If yes, explain the details.

The answers before and after showed an obvious progress in students' knowledge of sustainability and sustainable engineering approaches. Overall, at the beginning of the semester, a lot of students had the very limited knowledge of all of the questions. For question 1, most students' understanding was just about reducing pollution. For question 2 and 3, most students mentioned engineers could contribute to sustainability, but without knowing exactly how to. Several students mentioned designing durable products was sustainable engineering because it extended product life. For question 4, only 1 student out of 25 mentioned SolidWorks had sustainability evaluation function. For question 5, most students answered "I do not know", and several students mentioned some local industry's sustainability initiatives, either because they worked for these companies for their required co-op, or their family members work for these companies. Overall, students' knowledge and interest in sustainability are relatively low at the beginning of the semester.

These same questions were given again in the middle of the semester. Students' answer demonstrated their increase of awareness, interest, and knowledge about sustainability. For question 1, students were able to give a comprehensive explanation about sustainability. For question 2 and 3, students were able to realize that everyone could contribute to sustainable development: consumers through daily life through environmental lifestyles, engineers through technology and innovative designs, organizations through responsible plant management such as waste management. For questions 4, even though it was in the middle of the semester, students have not learned all sustainable engineering principles, they were still able to list a lot of tools, such as LCA, design optimation for reduced materials and so on. For question 5, students' answer varies from Walmart's sustainable packaging scoreboard to The Helios solar sailboat, a lot of the answers were not mentioned in class at all. This indicated the students had increased their interest to read more news about sustainable development. 
Learning Objectives Assessment through Coursework

Besides the students' self-evaluations, the course objectives were also assessed through course exams and project deliverables. Overall, students have demonstrated proficiency in the learning objectives. For example, in the midterm exam, the average grade for questions that tested learning objective a "students' understanding of the concept of sustainability, including the history, and laws related to sustainability" was $88.6 \%$ with a stand deviation of $7.2 \%$. Sample questions are "Why sustainability is important?" "What can engineers for sustainability?" "List 3 U.S sustainability policies or laws".

Learning objective b and c were assessed mainly through students' course projects deliverables. In the first phase of the project, the project group conducted Life Cycle Assessment for several product alternatives. The average grade for project phase 1 deliverables was $89.4 \%$ with a stand deviation of $5.1 \%$. Students were able to successfully to use LCA software to compare the environmental impacts of product alternatives. In the second phase of the project, the project groups designed new products with the aim to improve the environmental impact, using the techniques learned from the course. The average grade for project phase 2 deliverables was $88.9 \%$ with a standard deviation of $4.9 \%$.

\section{Discussion and future work}

Overall, the new sustainable design course was a success at Grand Valley State University to introduce the concept and engineering principles of sustainable engineering.

The next step will be assessing the impact of this course on how students make design decisions with the consideration of sustainability during capstone senior projects, which are industrysponsored projects with real-world applications.

In the future, it is hoped more collaboration with local community and industry could be built for this class, so the students could work on some projects that are beneficial to the community through service learning, and industry projects.

\section{Acknowledgement}

The authors would like to thank all students, guest speaker, facility managers involved in EGR 480 course for their support, assistance and constructive feedback.

\section{Bibliography}

[1] Accreditation Policy and Procedure Manual, ABET, 2017-2018 Accreditation Cycle. [2] M.L.Sattler, V.C.P.Chen, B.H.Dennis, S.Mattingly, K.J.Rogers, Y.P.Weatherton, M.Rani, and K.Kositkannawuth, "Integrating sustainability across the curriculum: Engineering Sustainable Engineers," Proceedings of the $119^{\text {th }}$ Annual Conference of ASEE, 2012, San Antonio, Texas. 
[3] Y.P.Weatherton, V.C.P.Chen, S.Mattingly, K.J.Rogers, and M.L.Sattler, “ Sustainable engineering internships: creation and assessment," Proceedings of the $119^{\text {th }}$ Annual Conference of ASEE, 2012, San Antonio, Texas.

[4] A. Bielefeldt, "Introducing first-year civil engineering students to sustainability," Proceedings of the $117^{\text {th }}$ Annual Conference of ASEE, 2010, Louisville, Kentucky. [5] N.V. Hernandez, H.A. Taboada, J. F. Espiritu, C. Gomez and I.A.Azuz, "Engineering Together Sustainable Communities: Sustainable Engineering in Action", Proceedings of the $123^{\text {rd }}$ Annual Conference of ASEE, 2016, New Orleans, LA.

[6] J. Meyhoff Fry, B.Hartlin, E.Wallen, and S. Aumonier, "Final report: Life Cycle Assessment of example packaging system for milk," WRAP, January 2010.

[7] R.H. Thaler and C.R. Sunstein, Nudge: Improving Decisions About Health, Wealth, and Happiness by Richard and Cass, London, England: Penguin Books, 2009.

[8] Picture copyright: https://worksthatwork.com/1/urinal-fly 